\title{
DR-30. PREPARATION OF LIGANDS FOR LANTHANIDE CATIONS BASED ON 5-ARYL-2,2'-BIPYRIDINE-6'-CARBOXYLIC ACIDS WITH AN EXTENDED CONJUGATION SYSTEM
}

\author{
A. P. Krinochkin ${ }^{1,2}$, D. S. Kopchuk ${ }^{1,2}$, S. Santra ${ }^{1}$, G. V. Zyryanov ${ }^{1,2}$, \\ V. L. Rusinov ${ }^{1,2}$, O. N. Chupakhin ${ }^{1,2}$ \\ ${ }^{1}$ Ural Federal University of the first President of Russia B. N. Yeltsin, \\ Mira St., 19, Yekaterinburg, 620002, Russia \\ ${ }^{2}$ I. Ya. Postovsky Institute of Organic Synthesis UB RAS, \\ S. Kovalevskoy/Akademicheskaya St., 20/22, Yekaterinburg, 620990, Russia \\ E-mail: yapet89@mail.ru
}

Luminescent lanthanide complexes are of interest from the point of view of creating OLEDs. At the same time, the proper ligand design is necessary from the point of view of the efficient transfer of excitation energy to the lanthanide cation, as well as the achievement of high solubility of the complex in non-polar organic solvents for the possibilities of its easy introduction into the OLED material. As a rule, lanthanide complexes based on beta diketones are used for this purpose. As an alternative, complexes based on 2,2'-bipyridine6-carboxylic acids can be considered, and we recently proposed a convenient way to increase the solubility of their complexes by annelation the cyclopentene fragment to one of the pyridine rings, which is achieved by using the «1,2,4-triazine methodology». Europium complexes of 5-aryl-2,2'-bipyridine-6'-carboxylic acids, including complexes with annelated cyclopentene fragment, showed interesting photophysical properties (quantum yield of phosphorescence up to $28 \%$ ). However, it was previously shown that the extension of the arylbipyridine conjugation system is very effective as a way to increase the quantum yield of the emission of such complexes. In this paper, we demonstrate the possibility of obtaining 5-aryl-2,2'-bipyridine-6'-carboxylic acids - ligands for lanthanide cations - with an extended conjugation system by means of the modification of the aromatic substituent.

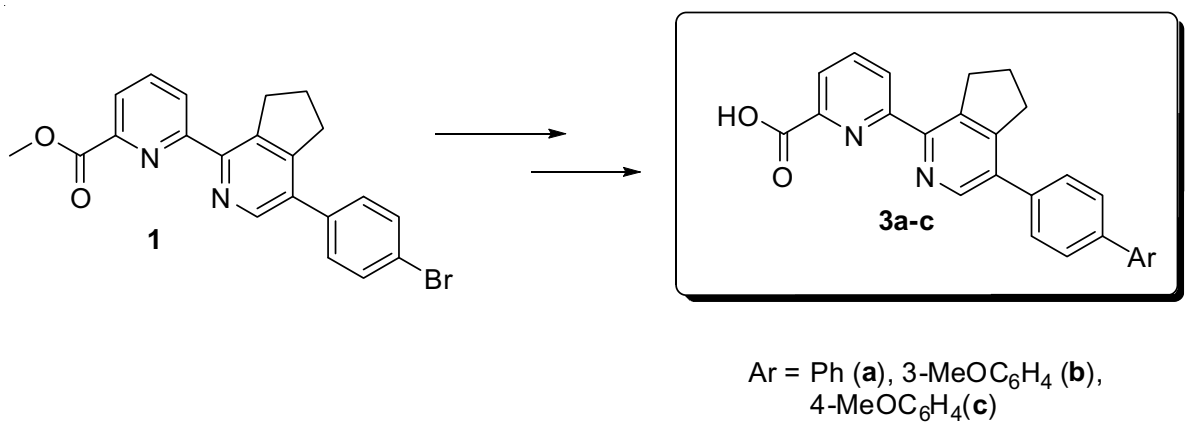

This work was supported by the Russian Science Foundation (Ref. № 18-73-10119). 